\title{
Sustainable Low Cost ANd High-Quality SuPPly Chain ASSURANCE-A SYSTEMATIC LITERATURE REVIEW
}

\author{
Maja Jokic, Danijela Gracanin \& Bojan Lalic
}
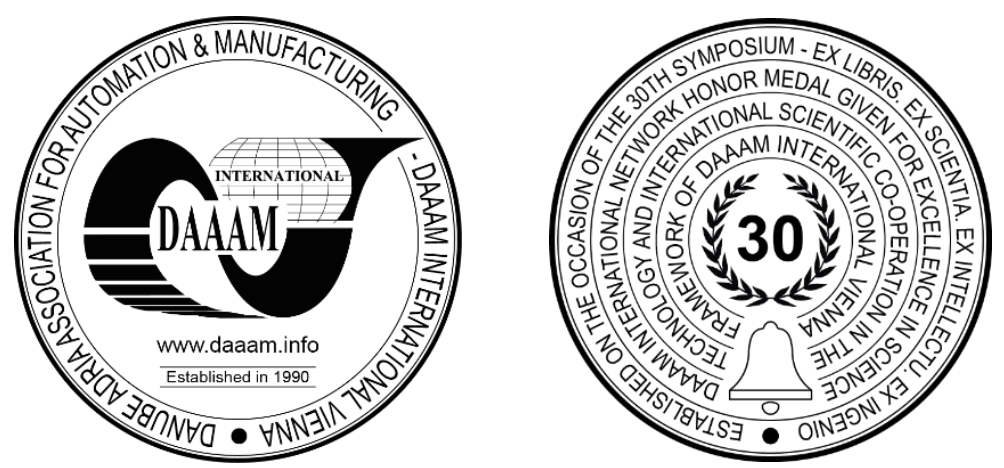

This Publication has to be referred as: Jokic, M[aja]; Gracanin, D[anijela] \& Lalic, B[ojan] (2019). Sustainable Low Cost and High-Quality Supply Chain Assurance-A Systematic Literature Review, Proceedings of the 30th DAAAM International Symposium, pp.1107-1114, B. Katalinic (Ed.), Published by DAAAM International, ISBN 978-3-90273422-8, ISSN 1726-9679, Vienna, Austria

DOI: $10.2507 / 30$ th.daaam.proceedings. 155

\begin{abstract}
From the early 70's till this day, myriad of research related to the topic of sustainability in supply chain was published. The research itself, has a global impact, as it considers sustainable processes that come as a solution for currently unsustainable behaviour of industries that deleteriously impact industry's costs and are lethal to the environment. Through the systematic literature review of provided papers, some valuable sustainable strategies and policies within the last decade, with the observation of 27 journals, proceedings and book chapters were commented. The literature review is here to investigate what was so far done for the creation of more sustainable propositions that gradually serve the development of new principles, policies and strategies to secure sustained low cost and high quality of supply chain activities. It will, as well, support the use of re-manufacturing practices in industries that predominantly and positively impact quality in supply chain, company's cost efficacy and finally the environment.
\end{abstract}

Keywords: supply chain quality; sustainable policy; re-manufacturing practices; sustainable strategy; literature review.

\section{Introduction}

Over the past decade, there have been numerous empirical studies that have tried to help companies to combat various challenges to provide sustainability to their actions in supply-chain management. Difference between points of view on how to tackle the existing issues such are trade-in policy making, poorly managed information sharing, dependency on raw materials, which strategies and policies promise profitability and quality of supply chain management, were creating problems for the augmentation of an absolute answer that may serve as a genuine guidance for legitimate supply-chain and manufacturing management within similar or fully divergent industries.

This research has focused its principles on two main targets: firstly, to more effectively comprehend what has been done so far in the field of achieving sustainability between supply chain processes and production process so one can promise more sustainable services; secondly, to which extant have strategies and policies in supply-chain changed so one can come up with the foremost sustainable gain in this sense. A sequence of accomplishments was observed for this systematic literature review. Certain approaches were taken into account for the endeavour of filling some missing 
literature gaps. By focusing on supply chain processes from re-.manufacturing perspective, sustainable policies and strategies were perceived for the creation of more proficient supply-chain services.

Two main research questions were established: 1. Is there an exclusive answer for the execution of sustainability that can be brought out within industries? 2. What are the most favourite sustainable strategies in supply-chain management, that are beneficial to the environment and profitability of the supply-chain service?

Global changes, pollution problems, economy and environmental ones, limited material consumption, have created uncertain times and uncertain costs which impact negatively on the societies, environment and therefore the equality of supply chain activities. The principles of sustainability to provide a solution to this problem have been used so far since the 1970's in practice. Reducing waste and adopting sustainable measures such are reuse, reduce, recycle, consider exception in energy and resource waste, reliance on non-renewable materials and significant cost reduction that mainly start with corrections within production processes. Therefore, to become fully sustainable, product supply-chain service needs to achieve sustainability in product manufacturing first.

\section{Research design and methodology}

The research design here is based on relevant papers that are prompted in 27 entitled research works. Standardization of the research was framed on the premises of: supply-chain management AND (policy OR strategy OR information sharing OR sustainability OR closed-loop OR analysis) AND (re-manufacturing OR sustainable models), which appeared in the research results as either keywords or within a title.

Chosen research studies were narrowed to conferences, journal articles and some of the book chapters within the last decade in order to achieve foremost difference between which suggestions of strategies and policies were given at the beginning of the executed period and what was improved later. All investigated works were presented in English with significant citation rates. The omission of other articles, journals and book-chapters was kept on the grounds of more trivial subjects, or the missing words such are: green supply-chain, re-manufacturing, sustainable strategies, sustainability, reverse logistics, production costs or supply-chain costs.

On contrary, data gathering was executed on provision of the relevant information to the: benefits of remanufacturing, green supply chain activities, environmental sustainability, product returns, product quality improvement and sustainable policy regulations. In addition, investigation was directed with the focal point on strategies and policies for the betterment of both manufacturing systems and supply-chain usage. The sense of the affiliation of supply-chain management and remanufacturing conventions was recognized as vital.

\section{Sustainable management of supply-chain}

Accustomed to the uncertainties in closed-loop supply chain, reverse supply chain promises adequate integration of key factors. This means that with the application of re-manufacturing principles within current supply-chain actions, sustained priority-based genetic and modified hybrid algorithms can optimize supply chain activities and its costs reduction [20]. As modelled and decentralized closed-loop supply chain are made on key suppliers and non-integrated manufacturers, actions of key suppliers and manufacturers have major impacts on economic and environmental performances of supply-chain. Therefore, it is logical to say that every integrated manufacturer and supplier is able to profit from remanufacturing in supply-chain management. Additionally, if one wants to enhance higher supply-chain quality, remanufacturing comes as a reasonable choice to make.

It is found that re-manufacturing practices develop diversity of the reverse flow in closed-loop supply chain that can further manage inventory of goods with broad diversity of possibilities. Substantially, this advocates creation of the sustainable supply-chain design for the reversal stream of the products for improved management of supply-chain. However, in supply-chain network, one should take into the account that as supply-chain network works on diverse levels, within that, establishing communication between the all bodies of supply chain network [21] up-stream and downstream(retailers, manufacturing companies, suppliers) and their customer-base, is complex but crucial for achieving balance among the supply and demand information.

With the attribution to the past research [9], contribution to the improvement of sustainability in supply chain in reverse flow during remanufacturing processes can be obtained. As it is pivotal, challenging sustainable activities within supply-chain management, has to be supported by right-on-time information sharing [20], and within that, has to be predominantly driven by allowance that all trading partners are acquainted with the demand signal so adequate sustainability among supply-chain entities can be achieved. Having said this, some valid answers to research questions are prevailed. 
Being that individuals do not comprehend the information sharing in equal terms, it is essential for managers, once they decide to go for re-manufacturing to adequately and clearly define newly adopted processes, in order to establish acceptable communications within different departments and functions so the benefits of re-manufacturing practices can be obtained. In order to avoid additional information flow disruption [9], or risking delay in supply-chain network, adoption of SCOR-modelling (Supply Chain Operations Reference (SCOR) model developed by Supply-Chain council as a valid tool for standardization of supply chain systems) for business optimization for the improvement of supply chain performances has been presented. By considering upstream and downstream information flow, material flow within supply chain networks is handled with SCOR [9] for the benefits of supply-chain activities. As quality of supply-chain highly depends on the simplification of material flow and the information/workflows of the exhibited supply-chain network, having this kind of approach is sustainable. Within this, quality of complex supply-chain is characterized by the magnitude of variable manufacturing costs that impact the equilibrium of the power that is spread across the reverse channel. Here the outsourcing is shown to perform better when it comes to shifting power to the third party, while inhouse approach gets more attention where control over costs cannot be lost [9].

It is as well [6] elaborated that a SCOR-modelling framework, being based on principles of re-engineering of business process, can positively impact the performance measurements in supply chain that significantly impact the quality of supply chain management.

Still, considering all the above mentioned, it is certain that the creation of sustainable or green supply chain [7] represents the sustainable business [11] of our future and promises stability for the companies and environment.

\section{Re-manufacturing}

Remanufacturing has been shown as an alterantive way for re-establishing the value of used materials in manufacturing. Perceived as an integrated process [27] various authors focused their research on methods such as LCM (Life Cycle Management), End-Of-Life Cycle [23], lean and cradle to grave method that are of cruciality to remanufacturing activities. By considering inputs and output into these methods, re-manufacturing sustains qualitative behavior towards the environment, through its procedures at the end-of-life cycle of product [23]. At this juncture, adjustments and the usage of the product lifecycle management are proposed as a attainable solution to the techniques for making outsorcing and in-house re-manufacturing more sustainable. The reasons are that through the above mentioned methods, one can observe ways in which product moves, grows, matures and disappears from the market and within that a company can cut unnecessary costs in other processes such is production or supply-chain.

In relation to supply-chain, acompanied by JIT (Just In Time) delivery option, re-manufacturing obtains the success within reverse logistics [12] by professionally managing the size and packaging appearance of delivered goods. The given adjustments are compared to the so called green supply chain where necessary material consumption are measured, in the sense, how much it is necessary for a manufacturer to supply materials during re-manufacturing process of the already used products/services and how much it is not.[14].

Additionally, by making improvements within production, and therefore within supply chain, chances for the creation of sustainable new product increase. This further creates a new age product that is ready to meet the expectations of customers, market and society [11],[13]. This creation in re-manufacturing [14] is costs efficiant, for both production and supply-chain processes, as it helps to sustain supply-chain efficancy towards the environment and opens new possibilities, new technologies for the implementation of the advanced profitable solutions in logistics.

As a thorough example of this, it is demonstrated that the implementation of the mixed integer nonlinear programming in manufacturing can susbtainatially maximise the profit of multi-echelon reverse logistics. Here, the case study within truck re-manufacturing processes has indicated [20] that the LINGO 8.0, optimization model (a software that is used for linear, non-linera and integer optimization of given methods for obtaining global optimum and quadratic solution of problems) has been used as a decision maker in regards with the most profitable number of facilities to be open for the observed cases. With considertaion of the number of their locations and the allocation of products flows, followed by sensitivity analysis, model has also introduced the maximum permissible distance between customers and initial collection points that play the significant role in boosting profitability. It is deduced that the deployment of retreated/remanufactured tires comes as a natural choice for both cusomers and companies [20] as retreated tires are sold for up to $50 \%$ discounts, while their mileage usage is still equal to new tires. Having this in mind, it can be concluded that with the application of smart logistic models, some of the factors that increase production costs (product demand, company's costs of production, material consumption, etc.) can be properly managed or avoided through the adoption of re-manufacturing procedures. 


\section{Re-manufacturing and supply-chain relation}

By using the same (or used, old) product in a different way, with the pivotal focus on the acquired sustainable practices and policies, and by indulging into a different case studies analysis, one can obtain cost reduction in supply chain thanks to re-manufacturing. Reversely, with the sustainable managing of supply-chain activities, profit maximization in remanufacturing procedures can be reached. Therein, prominence of supply-chain and re-manufacturing connection comes to an attention.

To accomplish valuable profitability in this service, some researchers have proposed methods that help to define and optimize monitoring and controlling activities within a supply-chain and logistics systems, and how those influence the costs of production and material performance. One of these is willingness of customers to purchase reused products. Two cases are shown [4] in which having a right-on-time sustainable policy implementation can trigger record profitability for the company and its supply-chain practices.

First, in which obtained profitability of a trade-in policy is at its peak at the time when buyback price of a product is insignificant, compared to the margin of delivering a new product. Second, at the so called "'sweet spot' [4] the spot where costs of acquisition and remanufacturing are at the minimum. This considers, that the time gap between the launching of new goods and commencing demand for remanufacturing of the same ones, are crossing at this spot. Here, the final observations on two lines: "sweet spot" and "time lag"[4], are made. It has been found that either though companies can impact these points, the time lag feature between those two is dependent on the time that marketing team in company makes for customers to believe in the remanufactured products or how much one is ready to believe in remanufacturing benefits [11].

In contrast, the deterioration of the manufacturing costs during re-manufacturing phase can significantly make supply chain network even more complex or deteriorate its quality. However, as stated before, the lost on quality predominantly depends on numerous other internal and external factors, such is: decision on how much a company desires to decide to invest in remanufacturing, as this is a question of their goals and awareness of sustainability needs [11].

So far, for better reconciliation between company's profitability and environmental efficiency in supply-chainremanufacturing matter, [25] it is crucial to recognise some of the conflicts that may arise from this relationship. Those are:

1. Conflicts with third party when the third party has higher channel power or when In-house strategy provides small fixed-costs; in this case, substantially power-determined retailer prefers less environmental strategy;

2. In the case when the remanufacturing process does not provide "'good-as-new" product, then the in-house retailer's preferences will choose new product or another that has a higher quality.

Still, there are some cases where third party subjects will chose low quality product if they find it more practical. In fact, the impact of production costs [13] boosts product quality and may cause manufacturers to go for re-manufacturing during the inauguration of new products, where the costs are reduced. During the re-manufacturing phase, producer will focus on the existing product quality improvement that will significantly cut the costs of additional procurement for materialas. By introducing a fuzzy network analysis that provokes fuzzy decision-making, the focus is on the circular supplier selection and order selection. Here, with the aid of mathematical modeling [13], fuzzy network analysis simplifies location search of the inventory and inaugurates minimization of supply-chain costs. This fuzzy solution is proven to be environmentally friendly as well for closed-loop supply chain management, as it prevents deadlocks for efficient delivery of products.

Therefore, if a company does a certain adjustment of quality in their service, there is a higher probability for them to properly locate their suppliers and inventories which further expands company's profitability on the market, rather than regulating the penalty for lesser product and lost service. In this way, mitigation of supply-chain risks within international supply-chain networking can be obtained. Having said that, profitability and hazard ratio of goods represent the essentiality in proper supply-chain managing [25]. In relation to this, it has been proven that with the growth of supervision probability, the hazard ratio deteriorates. Moreover, here the producer's financial gain expands, as the remanufacturing price and penance of second-class goods drops. With this kind of approach, both re-manufacturing processes and supplychain functions can financially gain.

In the interets of further subtle modification, intented changes in sustainable development need to be followed by policies. It is important to notice that ever first study in 1985. about supply-chain return policy was conducted by Pasternack [19]. Here the complexity of the supply-chain was brought to the basic one, where producer trades goods with retailer, with contract specification being a wholesale price. Moreover, product return policy [1] for disassembling, remanufacturing or testing, product on time penalty can be used as a part of adopted regulations efficiancy. 
Adequate remanufacturing policy can solve the problem of chosing suitable product quality of the returned product. Numerically, it is possible to show that companies can follow the flow of the product returns from consumers to the production facility and the flow of the sales. By offering certain stimulus policy [1], the observed company can expand the return rate of the products that will conduct elevated quality of the casted-off goods. From policy-makers perspective, short product quality improvement represents a pivotal element in chosing the proper strategy on whether to remanufacture product or just to improve its quality [5]. In order to obtain supply-chain coordination, return policy [1] gives retailer a time to use again unused or unsold goods. Choosfing the re-manufacturing as a prosperous strategy is crucial when manufacturing efficiancy is low, while on the other hand, when manufacturing efficiancy is soaring, there is no need to re-manufacture. Further on, product quality enhacement is preferable in that situation.

Authors [22] who have examined a two-echelon supply-chain in fashion industry and their sustainable policies have come to certain conclusions. When supply-chain obtains its cooperation, the cost for physical repayment of the goods is moderatly completed by supplier. Physical repayment impacts other activities such are: percentage on the return of the investment, scheduled sales of goods, predicted load of the leftovers. Compehensively describing, managing adequately surplus of the anticipated products can be constructive for economical and environmental sustainability. However, companies have to observe possible supplier selection as one of the foremost solutions for costs and environment efficiency [10].

Successful way to chose proper strategies is to adopt policy intervantions [16] such are: diminishing labour taxes, augmenting waste infrastructure that recognises differentiates assemblage for the reuse, and advocating the gathered data and depiction of the observed procedures. Those steps are essential for entities who want to avoid appearance of : soaring costs that deny return of the reused, recycled or re-manufactured products, scarcity of erratic policies and omission of firm's skill to ease the reused products.

Finding an abundant policy solution for all industries that will utterly provide sustainability for all industries at its all levels (ecology, economy, social) is likely impossible. However, [15] likelihood to develop a singular policy that may work for likely close industrial sectors. To elaborate further, if constructed in two-level structure, based on categorization framework, adopted sustainable policy for industry 4.0 can be implemented successfully among different industrial sectors such are: electronics, semiconductor and energy. In this way the research can render some valid information that can challenge the positive adoption of the newly acquired practices within logistics and supply chain management.

The represented methodological approaches are compromised out of literature reviews, that present the basis for the creation of vivid interpretations of stated methods that support the formation of sustainability among supply chain practices. By using words such are: sustainable supply chain practices/strategies, sustainable methods in remanufacturing, this literature review is providing valuable answers for observers.

For instance, it is [2] advocated that a supportive-decision tool, based on non-linear integer model can be used as an environmental alternative in supply-chain management that sustainably warehouses goods. Observations towards picking orders have developed four different steps of forklifting: transporting, picking and retrieving of the kept goods, where tool evaluates emissions.

This tool considers test cases with Diesel, LPG and an electric engine, to secure proper strategy picking for the minimization of external costs and environmental impacts. The results from the implementation of this method have provided some valuable insights; it is proven that the implication of it is wide and that it allows significant cost reduction in all mentioned cases with optimal results. Moreover, it is shown that notable cost reduction is attainable in supply chain, within divergent arrangements and designations of forklifts.

Additionally, choosing to re-manufacturing is profitable for supply-chain, however this is highly dependent on the division of the labor that exists within the reverse channel [25]. Other major factor that impact this decision making, are: willingness of the retailer to accept returned products, then consumer's readiness to pay for the re-manufactured products, then the range to which re-manufactured product jeopardizes request for the new product and the strength of such channel. Nonetheless, the situation here is contingent on the power which retailer enjoys compared to the third party [25]; in the case when retailer has higher power, he prefers higher salvage value of the product, while on contrary, it would rather choose lower salvage value when the third party is experiencing higher domination in the channel [9].

There are certain strategies that promote supply-chain profitability when re-manufacturing. Those compare the planned remanufacturing processes to the capacity of procurement of new materials[22] and involve "what-if" analysis. With the observations on take-back obligation in order to maintain "green image" effect on customer demand, "what-if" analysis is created to aid managers to observe both situations (green and not green) and accordingly make right decisions.

More to add, certain game-theories promise supply-chain advisability. By focusing on a single technology supplier and two production companies with two diverse products, Nash equilibrium, has shown to be predominantly useful for 
the achievement of a company's product sustainability and its profitable performance in supply-chain. It is [17] discovered that in petroleum industry, one can obtain sustainability on the price range matters. In the condition of competition between governments, individuals and private sector, where Mixed Integer Linear Programming (MILP) is used for the definition of optimal decision values in regards with the price range to achieve sustainable supply-chain practices in this industry.

Using Nash equilibrium is beneficial [26] as it is a game theory that helps creation of the best possible strategy of one player in relation to the other possible best strategy of the other player. The only condition here that has to be fulfilled is that both players do not change their strategies. To continue further, one of the suggestions that advantageously influence enterprises to choose best possible sustainable strategy is that Nash equilibrium is based on two (or more) diverse enterprises with two different products, where valuable data are picked and collected. Potentially the best strategy for achievements of price inauguration and technology ratification is chosen here. With the reflection on when it is the best to buy certain technology and how to sustain on the market with competing prices, deployment of asymmetric and symmetric Nash equilibrium attains price convenience to both supplier and manufacturer.

When Nash equilibrium is symmetric the creation of competitive price for both firms is hard as they struggle with the prisoner's dilemma (an enigmatic analytical approach where both parties consider that they will benefit at the cost of the other) that has influenced the deterioration of the profitability. While, when Nash equilibrium is asymmetric, more technological firms and entities prefer to purchase their peak profits. Moreover, if bodies that have higher power to impact price range, such are governments, decide to implement acceptable price range of technologies, then the willingness of the buyers will turn symmetric Nash equilibrium to asymmetrical one which will further benefit to the welfare of the whole society and companies. In this way for instance, the society itself can generate a situation which it can thoroughly exploit.

It has been proven that having a game theory for best strategy choosing, as a method for defining future profitability prediction [26] is predominant for strategy selection in profitability. Nash equilibrium is advantageous and can make a product/service acceptable not just for customers but for competitors that are also facing combative pricing. In this situation, companies and individuals are ready to create market rules and move towards their leadership roles.

\section{Conclusion}

With the consideration of: delivery on time, better product knowledge product excellence, and product return [18] additional benefits of remanufacturing are achieved in supply-chain service, e.g. deduction of harmful impact on the environment, as it minimizes waste for landfill and improves quality of the supply-chain service. Return policy can help suppliers to achieve brand new production, or aid retailers to receive sort of supporting money from their suppliers for fittingly organizing mislaying of unsold goods by the end of selling period. In this case usually products are asked to be shipped which is a casualty for both supplier and retailer-lost money [22].

Myriad of benefits and investments are attained thanks to the re-manufacturing. With the additional investments into: capital, market share, product development, service development, new labour, improvement of supply-chain processes, by investing into new technology and new knowledge etc., re-manufacturing can develop other sustainable ideas, such as possibilities of selling used materials to other companies or industries that the CEO and managers, find more acceptable.

Here two research questions were provided some valid answers: 1. there is no an unique sustainable strategy that can cover all industries, however a solution is given to those that are similar or the same, based on categorization framework of industries; 2. as for the most proficient strategy that can benefit both the environment and companies, it will have to be produced, either during planned profit pricing on a large scale and with the careful scrutiny on the environmental impacts, or as a policy that will affect downstream and upstream information flow of a supply chain, as a standardization of the supply chain quality in majority depends on the sustainable explanation of the material outflow.

As it is stated [16] recycling does not represent the best option for the environment, however a valid solution of remanufacturing is offered to combat lethal impacts of the recycling practices within supply-chain where shipping demolition is hazardous for the health and security of the nearby flora and fauna.

The limitations of this research are still that when observing friendly environmental perspective, re-manufacturing is mostly beneficial for the environment on a "per unit" basis, however, it can be damaging on a total amount of resources utilization. Moreover, adjusting and regulating policy return in supply-chain, does not necessarily promise better sustainable results than for instance regulating, as stated before, the wholesale pricing in those terms [22].

It is an engrossing fact that having sustainable solutions within supply-chain and manufacturing activities does not completely benefit the environment. Having endogenous supply-chain quality transformation in mind, scientists have explained "surroundings" in which remanufacturing manufacturer, considers completely opposite option rather than to 
enhance product or service quality, while a non-remanufacturing manufacturer does. Overall, remanufacturing is chosen when manufacturing costs of product quality improvement are slight.[9] Moreover, they have concluded that quality improvement is more common among a non-remanufacturer and that it can be additionally beneficial to the environment.[27], [2].

Other limits that have appeared through this systematic literature review are limited time and minor number of observed researches. Moreover, vast majority of the implemented solutions are based on a mathematical model, while empirical scrutiny is less illustrated. Furthermore, strategies and policies should accommodate longer pragmatic view. However, so far the research have made monumental improvement by offering faster and substantial competence by providing more advanced computer-integrated solutions, more productive observation of supply-chain management through multi-echelon investigation, likeness of reverse design networking of supply-chain flows, proficient ecoefficiency in policy making, and state-of-the-art usage of game theories in sustainable strategy planning.

Since that, the industries and researchers will be continuing with further research into this topic [11], [13], finding proper solutions, and within that the development, will be certain. Cost/effective solutions, emission problems will be gradually solved. Having this in mind, the prosperity of industries, will find its key achievements in supply-chain sustainability which, truthfully, will allow all agencies, governments, societies and companies to characterize the potential costs and resource savings with sustainable methods.

In this way, the performance of supply chain system will genuinely meet sustainable requirements of the markets and will establish methods for the comprehensive cost reduction. Having said that, the performance of re-manufacturing systems will naturally become more efficient and more effective [14]. By following this path, the research and industry will be able to generate justified sustainable conclusions.

On the basis of this literature review, some crucial impacts on strategy and policy making within manufacturing of goods and supplying of the same, can be investigated for the future research.

\section{References}

[1] Aksoy, H. \& Gupta, S. (2010). Near optimal buffer allocation in remanufacturing systems with N-policy. Computers and Industrial Engineering, Vol. 59, No. 4, (November 2010) page numbers (496-508), ISSN

[2] Boenzi,F.; Francesco, F., Digiesi, S., Facchini, F., Mossa, G. \& Mummolo, G. (2015). Greening activities in warehouses: a model for identifying sustainable strategies in material handling, Proceedings of the 26th DAAAM International Symposium, 26th DAAAM International Symposium on Intelligent Manufacturing and Automation. , Zadar, DOI: 10.2507/26th.daaam.proceedings.138.

[3] Buyukozkan,G. \& Cifci,G. (2010). A novel fuzzy multi-criteria decision framework for sustainable supplier selection with incomplete information. Computers in Industry,Vol. 62, No. 2, (February. 2011) page numbers (164174), ISSN

[4] Cole, D.; Mahapatra, S. \& Webster, S. (2017). A comparison of buyback and trade-in policies to acquire used products for remanufacturing. Journal of Business Logistics, Vol. 38, No. 3,(May 2017) page numbers(217-232), ISSN

[5] Danping, W.; Jing, L. \& Tiaojun, X. (2018). Impact of quality regulation policy on performance of a remanufacturing supply chain with non-waste returns. International Journal of Production Research, Vol. 57, No. 11,( December 2018) page numbers (3678-3694), ISSN

[6] Delipinar, G. \& Kocaoglu, B. (2016). Using SCOR model to gain competitive advantage: a literature review. Social and Behavioral Science, Vol. 229, (August 2016) page numbers (398-406), ISSN

[7] Eltayeb,T.; Zailani,S. \& Ramayah, T. (2010). Green supply chain initiatives among certified companies in Malayisa and environmental sustainability: investigating the outcomes. Resources, Conservation and Recycling, Vol. 55, No. 5, (March 2011) page numbers (495-506), ISSN

[8] Huang, C; Liang, W, Chuang, H. \& Chang, Z. (2012). A novel approach to product modularity and product disassembly with the consideration of 3R-abilities. Computers \& Industrial Engineering, Vol. 62, No.1,(February 2012) page numbers (96-107).

[9] Kremljak, Z. \& Kafol, C, (2015). Information technology support for supply chains. DAAAM International Scientific Book, Chapter 02, pp. 017-030.

[10] Kumar, A.; Jain, V. \& Kumar,S. (2013). A comprehensive environment friendly approach for supplier selection. Omega, Vol. 42, No. 1, (January 2014) page numbers (109-123), ISSN

[11] Lan, Y. (2011). Reengineering a green business. International Journal of Green Computing, Vol.2, No.1, (January 2011) page numbers (1-11), ISSN

[12] Lee, J. \& Lee, K. (2012). Modeling and optimization of closed-loop supply chain considering order of next arrival of goods. International Journal of Innovative Computing, Information and Control, Vol. 9, No. 9, (September 2013) page numbers (3639-3654), ISSN: 1349-4198 
[13] Li, G.; Reimann, M. \& Zhang, W. (2017). When remanufacturing meets product quality improvement: The impact of production cost. European Journal of Operational Research, Vol. 271., (June 2018) page numbers (913-925), ISSN

[14] Lin,R; Chen, R. \& Nguyen,T. (2011). Green supply chain management performance in automobile manufacturing industry under uncertainty. Procedia-Social and Behavioral Sciences, Vol. 25, (2011) page numbers (233-245), ISSN

[15] Lin, K.; Shyu, J. \& Ding, K. (2017). A cross-strait comparison of innovation policy under Industry 4.0 and sustainability development transition. MDPI Sustainability and Application of Green Technology, Vol 9, No. 5, (May 2017) page numbers (1-17), ISSN

[16] Milios, L.; Bequiri, B., Whalen, K. \& Jelonek, S. (2018). Sailing towards a circular economy: conditions for increased reuse and remanufacturing in the Scandinavian maritime sector. Journal of Cleaner Production, Vol. 225, (July 2019) page numbers (227-235), ISSN

[17] Moradinasab, N.; Amin-Naseri, M., Behbahani, T. \& Jafarzadeh, H. (2017). Competition and cooperation between supply chains in multi-objective petroleum green supply chain: A game theoretic approach,Journal of Cleaner Production, Vol. 170, (January 2018) page numbers (818-841), ISSN

[18] Nagalingam, S.; Kuik, S. \& Amer, Y. (2013). Performance measurement of product returns with recovery for sustainable manufacturing. Robotics and Computer-Integrated Manufacturing, Vol. 29, No. 6, (December 2013) page numbers (473-483), ISSN

[19] Pasternack, B. (1985). Optimal pricing and return policies for perishable commodities. Marketing Science, Vol. 4, No.2, (Spring, 1985) page numbers (166-176), ISSN: 07322399.

[20] Reyes, P.; Raisinghani, S. \& Singh, M. (2014).Global supply chain management in the telecommunications industry : the role of information technology in integration of supply chain entities. Journal of Global Information Technology management, Vol. 5, No. 2, (September 2014), page numbers(48-67), ISSN

[21] Sasikumar, P.; Kannan, G. \& Haq, A. (2010). A multi-echelon reverse logistics network design for product recoverya case of truck tire remanufacturing. The International Journal of Advanced Manufacturing Technology, Vol. 49, No. 9-12, (August 2010) page numbers (1223-1234), ISSN

[22] Shen, B. \& Li, Q. (2014). Impacts of returning unsold products in retail outsourcing fashion supply chain: a sustainability analysis. MDPI, Sustainability, Vol. 7, (January 2015) page numbers (1172-1185), ISSN: 2071-1050.

[23] Tsiliyannis, C. (2011). End-of-life flows of multiple cycle consumer products.Waste Management, Vol. 31, No. 11, (November 2011) page numbers (2302-2318), ISSN

[24] Turrisi, M.; Bruccolleri, M. \& Cannella, S. (2013). Impact of reverse logistics on supply chain performance. International Journal of Physical Distribution and Logistics Management, Vol. 43, No. 7, (August 2013) page numbers (564-585), ISSN: 0960-0035

[25] Wang, L.; Cai, G., Tsay, A. \& Vakharia, A. (2017). Design of the reverse channel for remanufacturing : must profitmaximization harm the environment?. Production and Operations Management Society, Vol. 26, No 8, (March 2017) page numbers (1585-1603), ISSN

[26] Xiaoduo, Q.; Wei, L. \& Jiaquan, Y. (2018). Game theory analysis of technology adoption timing and pricing decision in supply chain system under asymmetric Nash equilibrium. Journal of Intelligent \& Fuzzy Systems, Vol. 35, No.3, (October 2018) page numbers (3101-3111), ISSN

[27] Xiong, Y.; Zhou, Y., Li, G., Chan, H. \& Xiong,Z. (2013). Don't forget your supplier when remanufacturing. European Journal Of Operational Research, Vol. 230, No.1, (October 2013) page numbers (15-25), ISSN 